\title{
Could predicting fatty acid profile by mid-infrared reflectance spectroscopy be used as a method to increase the value added by milk production chains?
}

\author{
M. Coppa, ${ }^{*}$ A. Revello-Chion, † D. Giaccone,† E. Tabacco, ${ }^{*}$ and G. Borreani ${ }^{* 1}$ \\ *Department of Agricultural, Forest and Food Sciences (DISAFA), University of Turin, Largo P. Braccini 2, 10095, Grugliasco (Turin), Italy \\ †Associazione Regionale Allevatori del Piemonte, Via Livorno 60, 10144, Turin, Italy
}

\begin{abstract}
The aims of this work were (1) to develop prediction equations from mid-infrared spectroscopy (MIRS) to establish a detailed fatty acid (FA) composition of milk; (2) to propose a milk FA index, utilizing MIRS-developed equations, in which the precision of the FA-prediction equations is taken into account to increase the value of milk; and (3) to show application examples. A total of 651 bulk cow milk samples were collected from 245 commercial farms in northwest Italy. The results of the 651 gas chromatography analyses were used to establish (421 samples) and to validate (230 samples) the outcomes of the FA composition prediction that had been obtained by MIRS. A classbased approach, in which the obtained MIRS equations were used, was proposed to define a milk classification. The method provides a numerical index [milk FA index (MFAI)] that allows a premium price to be quantified to increase the value of a favorable FA profile of milk. Ten FA were selected to calculate MFAI, according to their relevance for human health and potential cheese sensory properties, and animal welfare and environmental sustainability were also considered. These factors were selected as dimensions of MFAI. A statistical analysis and expert judgment aggregation were performed on the selected FA by weighting the FA and normalizing the dimensions to reduce redundancy. A class approach was applied, using the precision of the MIRS equations to establish the classes. The median FA concentration of the data set was set as a reference value of class 0 . The width, number, and limits of classes above and below the median were calculated using the $95 \%$ confidence level of the standard error of prediction, corrected with the bias of each FA. A progressive number and a positive or negative sign were assigned to each FA class above or below the median according to their role in the above mentioned dimensions. The sum of the
\end{abstract}

Received December 1, 2016.

Accepted July 20, 2017.

${ }^{1}$ Corresponding author: giorgio.borreani@unito.it numbers of each class, associated with its sign for each FA, was used to generate MFAI. The MFAI was applied to dairy farms characterized by different feeding strategies, all of which deliver milk to a commercial dairy plant. The MFAI values ranged from 0.7 to 4.2 , and large variations, which depended on the cows' diet and forage quality, were observed for each feeding system. The proposed method has been found to be flexible and adaptable to several contexts on both intensive and extensive dairy farms.

Key words: mid-infrared reflectance spectroscopy, milk fatty acid profile, milk payment index

\section{INTRODUCTION}

Dairy products are important fat and medium-chain SFA sources in the human diet in western Europe (FAO, 2016); moreover, they provide high-quality protein, essential micronutrients, and several bioactive lipids (Shingfield et al., 2013). Therefore, the milk fatty acid (FA) composition has been studied in great detail, for its importance on human health, and in particular on cardiovascular diseases and cancer, and in the modulation of immune and inflammatory responses (Parodi, 2004; Givens, 2010; Dilzer and Park, 2012). Moreover, some FA are relevant for human nutrition, as they cannot be synthesized by the human body (Stark et al., 2008). Over the last $100 \mathrm{yr}$, the human diet has been modified, with a huge increase in animal product consumption, and thus in fat intake, as well as a qualitative modification of the ingestion of n- 6 FA and a concomitant reduction in foods rich in n-3 FA (Caramia and Ruffini, 2005). These dietary changes have altered the ratio between the intake of the n- 3 and n- 6 FA, whose value has moved from close to 1:1 to 1:20. These dietary changes, combined with other environmental changes, such as physical inactivity, hypertension, smoking, and so on, are considered among the main causes of the rapid increase in diet-related chronic diseases over the last century (Parodi, 2004; Caramia and Ruffini, 2005).

The FA composition of milk also plays a key role in the sensory properties of dairy products (Martin et al., 
2005; Giaccone et al., 2016) and can offer information about the ruminal functionality and health status of the animal (Bauman and Griinari, 2003; Vlaeminck et al., 2006). Thus, consumers all over the world are demanding a greater health-promoting FA composition of milk and dairy products, and this has led dairy companies to be interested in exploring potential marketing opportunities to adapt their milk production systems to consumer demands (Diekman and Malcolm, 2009; Borreani et al., 2013; Silva-Villacorta, 2014). Milk FA content has shown high elasticity, mainly due to feeding strategies, and can be modified on-farm by feeding cows fresh and high-quality conserved forages (RevelloChion et al., 2010; Coppa et al., 2015b), oilseeds, and marine oils (Chilliard et al., 2001, 2007; Hurtaud et al., 2014) or genetically through animal selection (De Marchi et al., 2014). Some studies have shown that the adoption of on-farm (diet formulation) strategies for the production of milk with improved FA profiles can have a negative effect on farm profit if the milk payment system does not include a premium for the FA concentration (Chilliard et al., 2001; Silva-Villacorta et al., 2016). This has led to the need for a fast and economic tool that can be used for the FA analysis of milk and for the development of strategies to pay supplementary premiums to dairy farmers (Stefanov et al., 2011; Coppa et al., 2014).

Mid-infrared reflectance spectroscopy (MIRS) has been proposed as a new, inexpensive, and rapid tool for the FA analysis of milk, especially because it can overcome the problems connected to the expensive and time consuming GC methods (Soyeurt et al., 2006). To our knowledge, MIRS prediction equations pertaining to FA and FA sums have already been developed for milk samples from individual cows. However, prediction equations for a detailed FA profile of bulk milk from commercial farms are still not available. The equations for the main FA or their sum have shown comparable performances in different studies (Soyeurt et al., 2006; Maurice-Van Eijndhoven et al., 2013; Ferrand-Calmels et al., 2014), but highly reliable predictions have only been obtained for few FA, and the majority have only been predicted approximately (Soyeurt et al., 2011; Ferrand-Calmels et al., 2014). As no indications on the practical use of MIRS equations (i.e., for milk payment, breeding purposes), taking into account their reliability level, have been given in any previous study, the careful use of the equations that have shown low reliability is recommended. The aims of our work were (1) to develop prediction equations, obtained from MIRS, to establish a detailed FA composition of milk; (2) to propose a milk FA index (MFAI) utilizing MIRS developed equations that take into account the precision of the FA predic- tion equations; and (3) to offer application examples of MFAI adding value to milk by paying a premium price based on a favorable FA profile.

\section{MATERIALS AND METHODS}

\section{Milk Sampling and Survey}

A total of 651 bulk cow milk samples were collected from 245 commercial farms, located in northwest Italy, from 2013 to 2015 to improve calibration equations for the main FA of milk and for their sums and ratios obtained from MIRS, as reported in Coppa et al. (2014). To explore the maximum variability of the FA composition of milk from commercial farms, samples were collected in different seasons from several dairy farms, including most of the farming systems and formulation diet strategies adopted in northern Italy, ranging from the intensive farms of the plain to the extensive farms of the Alps.

About $1 \mathrm{~L}$ of bulk milk was collected on each farm and transported at $4^{\circ} \mathrm{C}$, without any added preservative, to the laboratory for later analyses. Each sample was then divided into 2 subsamples: 1 for FA reference analysis by means of GC, and 1 for MIRS analysis. Data on the production conditions were recorded on farm at each sampling by compiling a detailed questionnaire drawn up by Borreani et al. (2013).

\section{FA GC Analysis}

The FA analyses, conducted by means of the reference GC method, were performed according to Coppa et al. (2014). Briefly, milk was centrifuged at $3,700 \times$ $g$ for $15 \mathrm{~min}$ at $4^{\circ} \mathrm{C}$ to separate the cream, which was further centrifuged at $20,000 \times g$ for $35 \mathrm{~min}$ at $35^{\circ} \mathrm{C}$ to separate the anhydrous fat, according to RevelloChion et al. (2010). Fatty acid transesterification was obtained according to Revello-Chion et al. (2010). The FAME were analyzed using a 7890A GC-System (Agilent Technologies, Santa Clara, CA) equipped with a flame ionization detector. The FAME were separated on a $100 \mathrm{~m} \times 0.25 \mathrm{~mm}$ i.d. fused-silica capillary column (CP-Sil 88, Chrompack, Middelburg, the Netherlands). The injector temperature was maintained at $250^{\circ} \mathrm{C}$ and the detector temperature was kept at $255^{\circ} \mathrm{C}$. The initial temperature in the oven was held at $70^{\circ} \mathrm{C}$ for $1 \mathrm{~min}$, increased by $5^{\circ} \mathrm{C} / \mathrm{min}$ to $100^{\circ} \mathrm{C}$ (held for $2 \mathrm{~min}$ ), then increased by $10^{\circ} \mathrm{C} / \mathrm{min}$ to $175^{\circ} \mathrm{C}$ (held for $40 \mathrm{~min}$ ) and $5^{\circ} \mathrm{C} / \mathrm{min}$ to a final temperature of $225^{\circ} \mathrm{C}$ (held for 15 min). The carrier gas was hydrogen. The FA concentrations were measured by means of the reference GC method as grams per $100 \mathrm{~g}$ of FA. 


\section{Infrared Analysis}

The subsamples for MIRS analysis $(50 \mathrm{~mL})$ were analyzed using Fourier transform mid-infrared spectroscopy (MilkoScan FT6000, Foss, Hillerød, Denmark), working within the MIR region from 1,000 to $5,000 / \mathrm{cm}$, and according to IDF (2000).

\section{Calibration and Statistics}

The results of 421 samples were used for calibration purposes, and the results of 230 samples from farms not included in the calibration set were used for validation, making sure similar proportions of the different feeding systems were considered in the 2 data sets. Calibrations of the FA predictions were performed using WinISI II Project Manager, version 1.50 (Infrasoft International, State College, PA) and calculated with modified partial least square regression (Shenk and Westerhaus, 1995), which had shown better performance than partial least square regression. For the same reason, only 2 different correction procedures were applied to the raw data: no correction and detrend. Moreover, only first-order gap derivation $(1,4,4,1)$ was used as the mathematical treatment. A repeatability file was included for each infrared calibration during the development of the equations (Westerhaus, 1990; Soyeurt et al., 2011). Regressions were developed with the full spectrum (Coppa et al., 2014), the 3 mid-infrared regions located between 926 and $1,600 / \mathrm{cm}$, between 1,712 and $1,809 / \mathrm{cm}$, and between 2,561 and 2,989/cm according to MauriceVan Eijndhoven et al. (2013), and the 3 MIR regions located between 1,050 and $1,600 / \mathrm{cm}$, between 1,736 and $1,805 / \mathrm{cm}$, and between 2,823 and $3,016 / \mathrm{cm}$ used by De Marchi et al. (2011) as the principal regions to estimate the FA composition of milk. Regressions were developed for FA reference data expressed as grams per $100 \mathrm{~g}$ of FA. The sums and ratios of the individual FA were calculated for a total of 5 sums and 8 ratios, as described in Coppa et al. (2014). The atherogenic and thrombogenic indexes were calculated according to Ulbricht and Southgate (1991). A 16 latent variable calculation was set for each regression calculation, and critical values (Student's $\mathrm{T}$ ) of $\mathrm{T}=2.5$ were adopted to remove any calibration outliers. Two elimination passes were conducted and full cross-validation (6 cross-validation groups) was used. The statistics used to develop and evaluate the calibration models included the standard error of cross-validation, the coefficient of determination for cross-validation $\left(\mathbf{R}^{2} \mathbf{C V}\right)$, the coefficient of determination in external validation $\left(\mathbf{R}^{2} \mathbf{V}\right)$, the standard error of prediction (SEP), the slope, the bias and the standard error of prediction corrected by the bias of the validation set, and the ratio of the stan- dard deviation of the reference data to the standard error of cross-validation (RPD). The RPD statistics provide a basis for standardizing the SEP (Williams and Sobering, 1993). According to Coppa et al. (2014), predictions were classified as poor, approximate, promising, or reliable for a lower $R^{2}$ (both $R^{2} C V$ and $R^{2} V$ ) value than 0.66 , between 0.66 and 0.81 , between 0.81 and 0.90 , and higher above 0.90 , respectively.

To test for any possible relationship between the individual FA concentrations in the milk (expressed as grams per $100 \mathrm{~g}$ of $\mathrm{FA}$; as obtained from the GC analysis), their prediction performances, and milk fat content, a Pearson correlation analysis was performed between the FA and the milk fat content, using SPSS for Windows software (version 17.0; SPSS Inc., Chicago, IL). The validation performances were compared using the procedure proposed by Shenk (1989), which identifies significant biases or increases in unexplained errors through the standard error of prediction corrected by the bias.

\section{Method for the Calculation of MFAI Using MIRS Prediction Equations}

Definition of FA Classes. Differences in the ability to predict FA concentrations were expected, and careful use of the equations with approximate or poor prediction had to be considered. Thus, a method was proposed to overcome the performance limits of the equations with high SEP; the class-based approach described by Mantha et al. (1993) was adopted. In this approach, each class has a central FA concentration value and an upper and lower limit. These limits were calculated as the central concentration \pm the confidence interval $(\mathbf{C I})$ at $P=0.95$, calculated as SEP $\times 1.96$ (Kirkwood and Sterne, 2003). The higher the SEP, the larger the classes (Mantha et al., 1993). The median of the whole distribution of an FA was set as a reference value of the central class (class 0), except for those FA for which a recognized threshold for specific effects was found in the literature (i.e., on sensory properties or animal welfare), as explained hereafter. For example, MUFA have a central class 0 value equal to $28.31 \mathrm{~g} / 100 \mathrm{~g}$ of FA, whose limits were found to be $28.31 \pm 1.13(\mathrm{CI})$; thus, 27.17 and $29.44 \mathrm{~g} / 100 \mathrm{~g}$ of FA for the lower and upper limits, respectively. The lower limit of the subsequent growing $(\mathbf{G})$ class (class G1) was used as the upper limit of the previous class (class 0; i.e., for MUFA $29.44 \mathrm{~g} / 100 \mathrm{~g}$ of FA was the upper limit of class 0 and the lower limit of class 1 ); the nominal value of class G1 was calculated as the lower limit of the class plus CI (i.e., for MUFA $29.44+$ $1.13=30.57$ ), whereas the upper limit of class G1 was calculated as the nominal value of class G1 plus CI; and 
so on for class Gn. When there was less than twice the CI over the upper limit of the Gn class, the latter class was merged with the previous one, and the maximum value was set as the upper limit. This approach allows any possible distortive effect of extreme values to be avoided. The same method was applied to determine the decreasing (D) classes (classes D1, D2, and Dn). The class approach, based on the performance limits of the equations using SEP to establish the class, implies that the classes do not reflect the population, but it ensures a reliable estimation.

Set of FA for a Calculation Example of the MFAI. Considering the previously discussed aspects, a set of FA, or their sums and ratios, can be selected according to the local farming conditions of a geographical area, the breeding purposes, or the marketing strategies of a dairy plant. To show a possible application of the proposed milk FA valorization method, an example of practical use of MFAI was formulated. The following 10 individual FA, sum, and ratios with at least 2 classes more than class 0 were selected: C18: 3n-3, CLA cis-9,trans-11, even-chain SFA, branchedchain FA (BCFA), MUFA, PUFA, the sum of n-3, the n-3-to-n-6 ratio, the C18:1 cis-9-to-C16:0 ratio, and the C18:1 trans-10-to-C18:1 trans-11 ratio (Table 1). These FA were grouped in 2 main categories of equivalent importance for dairy products, according to (1) their direct effect on human health and nutrition and (2) their effect on dairy industries and marketing strategies (Table 1). The latter category was further divided into 3 subcategories on the basis of the role of the FA (1) in the definition of sensory properties of dairy products, (2) as an indicator of animal welfare, or (3) as an indicator of environmental sustainability (Table 1). Each FA can be included in more than 1 pillar (or subpillar) if it can be recognized to play a role in different aspects (i.e., human nutrition and environmental sustainability). The rationale behind the attribution of an FA to a pillar or subpillar is presented.

Human Nutrition Category. A positive sign was attributed to high concentrations of MUFA, PUFA, C18:3n-3, total n-3 FA, and of the n-3-to-n-6 ratio according to their effect on lowering the risk factors of cardiovascular disease (Parodi, 2004; Dawczynski et al., 2010; Givens, 2010). High concentrations of CLA cis9,trans-11 and BCFA were also given a positive sign, as they may concur in reducing body fat, cardiovascular diseases, and cancer, in modulating immune and inflammatory responses, and in improving bone mass (Vlaeminck et al., 2006; Dilzer and Park, 2012). Similarly, a negative sign was attributed to high concentrations of even-chain SFA, as their excess consumption has been associated with negative effects on cholesterolemia and coronary heart diseases (Parodi, 2004; Givens, 2010).

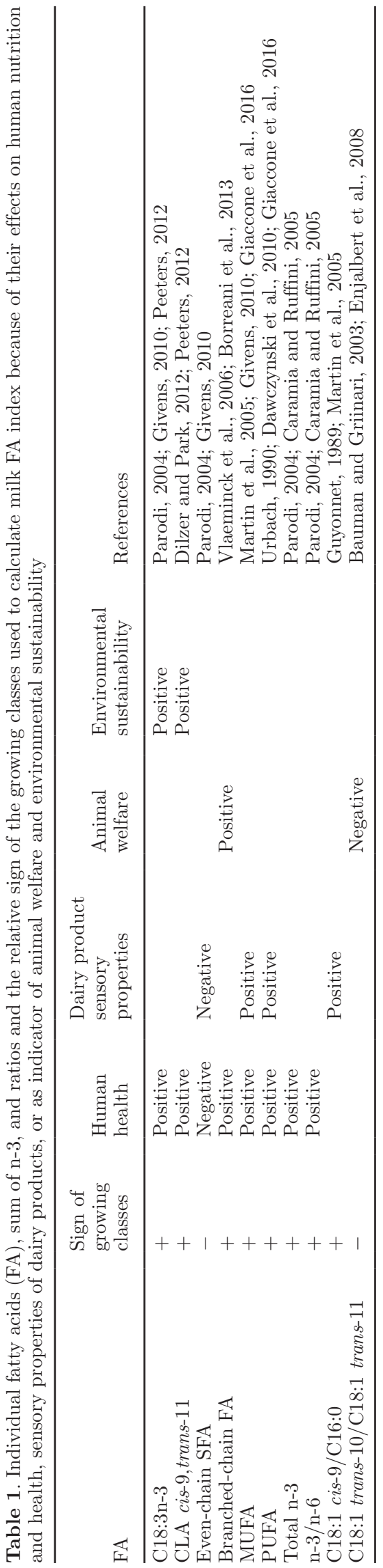

Journal of Dairy Science Vol. 100 No. 11, 2017 
Table 2. Pearson's correlation coefficients among the fatty acids (FA) used in the milk FA index

\begin{tabular}{|c|c|c|c|c|c|c|c|c|c|}
\hline $\begin{array}{l}\mathrm{FA}^{1} \\
(\mathrm{~g} / 100 \mathrm{~g} \text { of } \mathrm{FA})\end{array}$ & C18:3n-3 & $\begin{array}{l}\text { CLA cis-9, } \\
\text { trans- } 11\end{array}$ & $\begin{array}{l}\text { Even-chain } \\
\text { SFA }\end{array}$ & $\begin{array}{l}\text { Branched- } \\
\text { chain FA }\end{array}$ & MUFA & PUFA & $\begin{array}{c}\text { Total } \\
\text { n-3 }\end{array}$ & $\begin{array}{c}\mathrm{n}-3 / \\
\mathrm{n}-6\end{array}$ & $\begin{array}{l}\text { C18:1 cis-9/ } \\
\text { C16:0 }\end{array}$ \\
\hline CLA cis-9,trans- 11 & 0.78 & & & & & & & & \\
\hline MUFA & 0.48 & 0.62 & -0.94 & 0.40 & & & & & \\
\hline PUFA & 0.76 & 0.75 & -0.76 & 0.35 & 0.58 & & & & \\
\hline Total n-3 & 0.99 & 0.79 & -0.71 & 0.73 & 0.48 & 0.75 & & & \\
\hline C18:1 trans-10/C18:1 trans-11 & -0.52 & -0.51 & 0.33 & -0.67 & -0.19 & -0.21 & -0.53 & -0.60 & -0.43 \\
\hline
\end{tabular}

${ }^{1} P$-value $<0.001$ for all the correlations.

Sensory Properties of Dairy Products. A richness in PUFA has been associated with a richness in odor-active compounds in milk or cheese (Urbach, 1990). High concentrations of even-chain SFA and low concentrations of MUFA and PUFA reduce the fat melting point and confer increased firmness, as well as reduced melting ability and creaminess to butter and cheese (Martin et al., 2005). Consequently negative and positive signs were given to these FA, respectively. The C18:1 cis-9-to-C16:0 ratio, also known as the spreadability index, was found to be correlated with butter and cheese texture (Martin et al., 2005). Guyonnet (1989) identified 0.77 as the threshold for the C18:1 cis-9-to-C16:0 ratio, over which differences in butter texture can be perceptible and appreciated by consumers. Consequently, 0.77 was used to calculate the class 0 limits for the $\mathrm{C} 18: 1$ cis-9-to-C16:0 ratio instead of the median of the population. This value was set as the upper limit of class 0 , and a positive sign was associated with higher values.

Animal Welfare. The FA in milk can be also indirect indicators of ruminal functionality and animal health status (Bauman and Griinari, 2003). Higher values of the C18:1 trans-10-to-C8:1 trans-11 ratio in milk than 1.00 can be indicators of possible subacute ruminal acidosis (Enjalbert et al., 2008). Thus, 1.00 was set as the upper limit of class 0 for the C18:1 trans-10-to-C8:1 trans-11 ratio, and a negative sign was associated with higher values. Furthermore, BCFA decrease, as the fiber proportion in the cow diet decreases (Vlaeminck et al., 2006; Borreani et al., 2013; Coppa et al., 2015b), favoring ruminal metabolic disorders (Bauman and Griinari, 2003); consequently, a positive sign was assigned to the BCFA concentration in milk.

Environmental Sustainability. Grassland increases soil carbon storage and biodiversity compared with arable lands and decreases water pollution and soil erosion (Peeters, 2012; Arnould et al., 2013). Increasing the grassland-derived forages in cow diets and reducing cereals and concentrates induces increases in CLA cis-9,trans-11 and C18:3 n-3 in milk (Hurtaud et al., 2014; Coppa et al., 2015b). Furthermore, cows grazing on permanent and highly biodiversified lowinput grasslands have shown a high concentration of C18:3 n-3 in their milk (Chilliard et al., 2007; Coppa et al., 2015b). Thus, high concentrations of C18:3 n-3

Table 3. Maximal normalized weigh of each fatty acid (FA) within each subpillar used for the calculation of milk FA index

\begin{tabular}{|c|c|c|c|}
\hline Pillar & Subpillar & Fatty acid & Normalized weight \\
\hline \multirow{5}{*}{ Human health $(\mathrm{HH})$} & & CLA cis-9,trans- 11 & 1.0 \\
\hline & & Even-chain SFA & 0.5 \\
\hline & & MUFA & 0.5 \\
\hline & & PUFA & 1.0 \\
\hline & & Total n-3 & 0.25 \\
\hline \multirow{6}{*}{ Dairy industry } & & MUFA & 0.28 \\
\hline & & PUFA & 0.83 \\
\hline & & $\mathrm{C} 18: 1$ cis-9/C16:0 & 0.28 \\
\hline & Animal welfare (AW) & Branched-chain FA & 0.83 \\
\hline & & $\begin{array}{l}\text { C18:1 trans-10/C18:1 } \\
\text { trans-11 }\end{array}$ & 0.83 \\
\hline & Environmental sustainability (ES) & C18:3n-3 & 0.83 \\
\hline
\end{tabular}


Table 4. Descriptive statistics of milk fatty acid (FA) composition in the calibration and validation sets

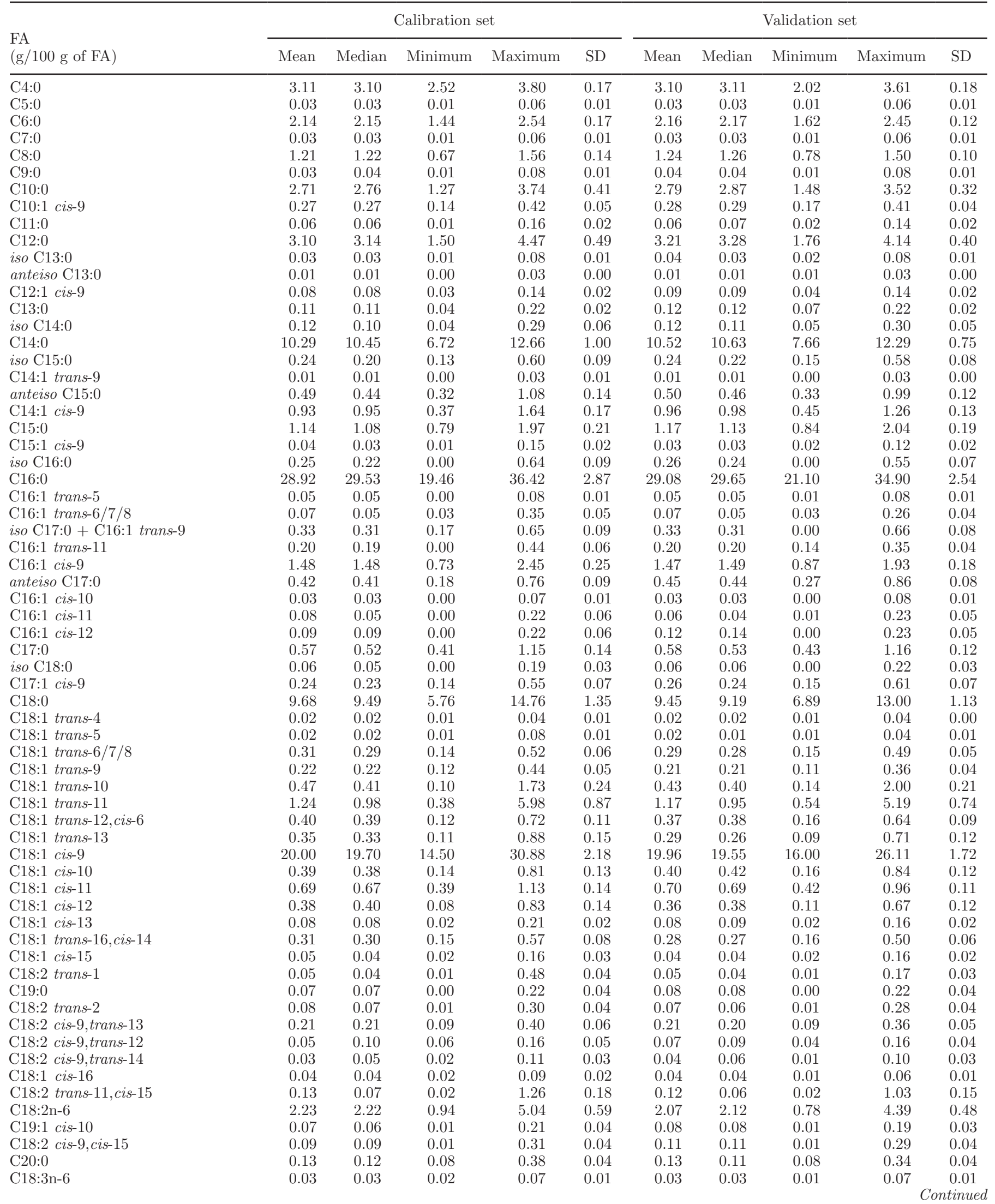


Table 4 (Continued). Descriptive statistics of milk fatty acid (FA) composition in the calibration and validation sets

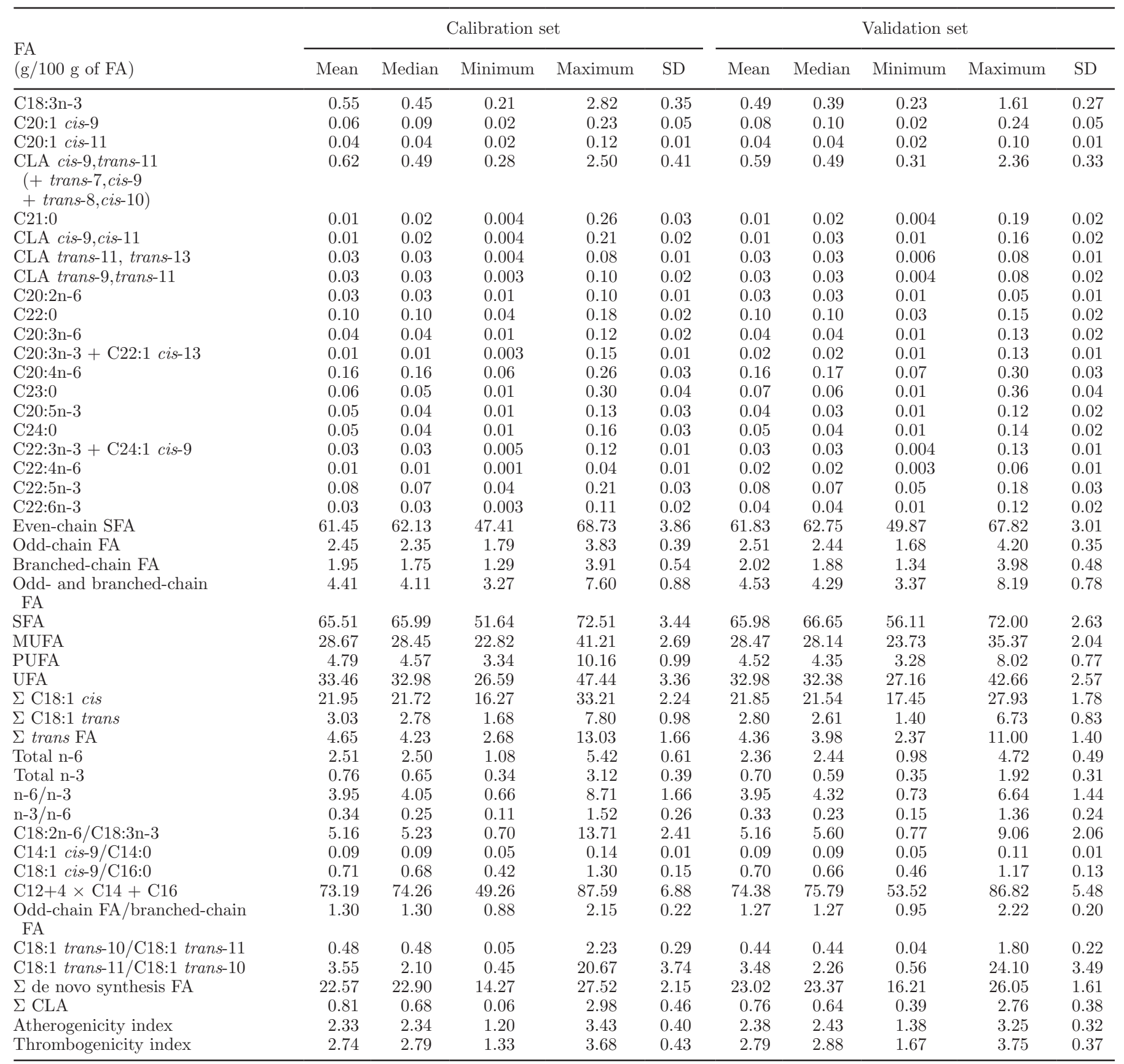

and CLA cis-9,trans-11 can be indirect indicators of the environmental sustainability of a dairy farming system, and a positive sign was therefore given to high concentrations of these 2 FA.

Weighting Procedure to Calculate MFAI. The weighting procedure to calculate MFAI was developed according to Paracchini et al. (2015). The initial assumption was that all the selected FA within each pillar or subpillar had the same weight. Thus, the FA were normalized by attributing a hierarchical range of a point from 0 to 1 to each FA, in which 0 was assigned to the lowest decreasing class or the highest growing class for those FA with a positive or negative sign, respectively, and 1 to the highest increasing or to the lowest decreasing class, respectively. According to the procedure proposed by Nardo et al. (2008), a Pearson correlation analysis was performed on all the FA included in the same subpillar (Table 2) to identify high correlation cases that could require the application of weights (Paracchini et al., 2015), which is required to avoid an 
Table 5. Mid-infrared prediction results for fatty acid (FA) composition in calibration and validation data sets

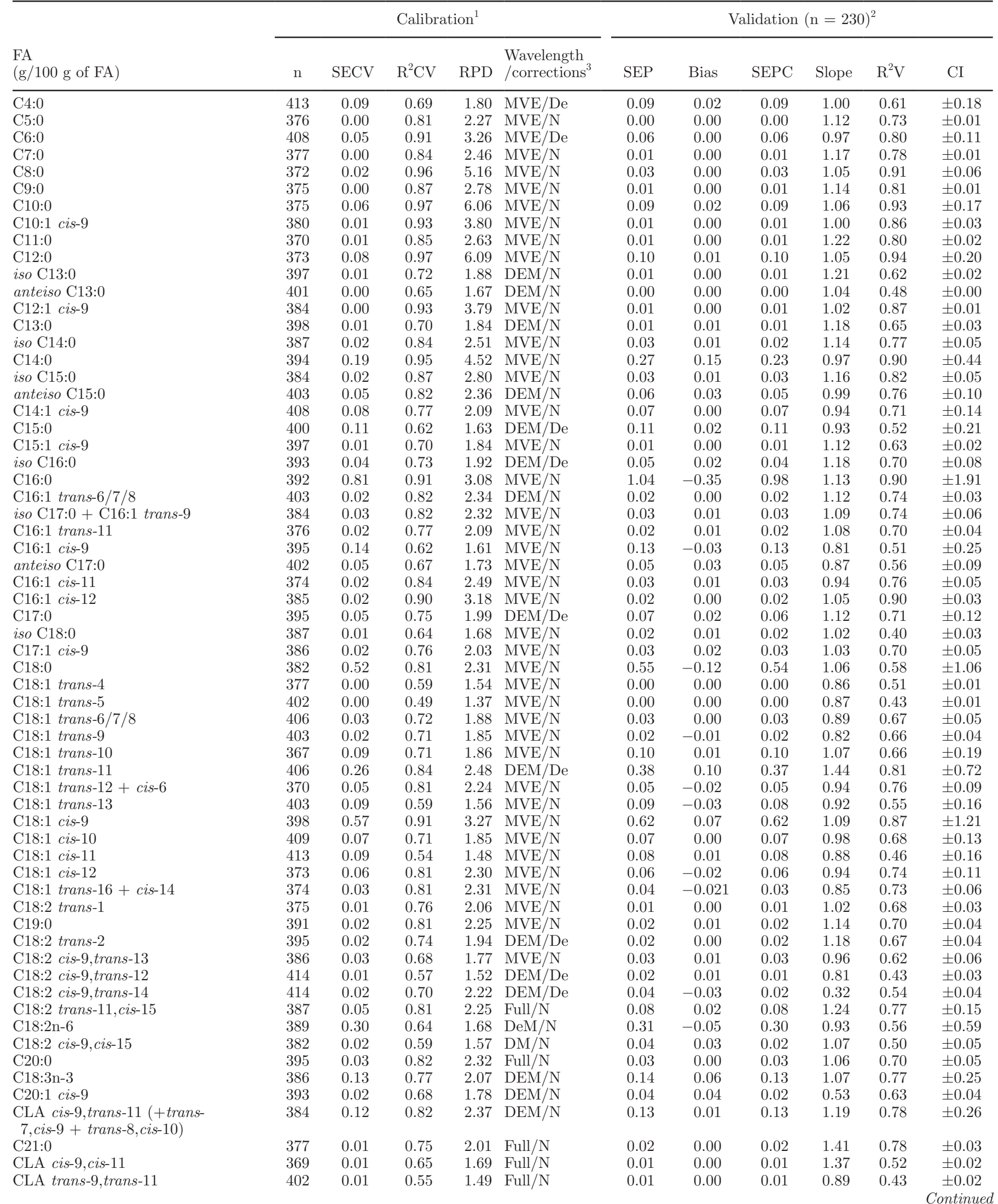


Table 5 (Continued). Mid-infrared prediction results for fatty acid (FA) composition in calibration and validation data sets

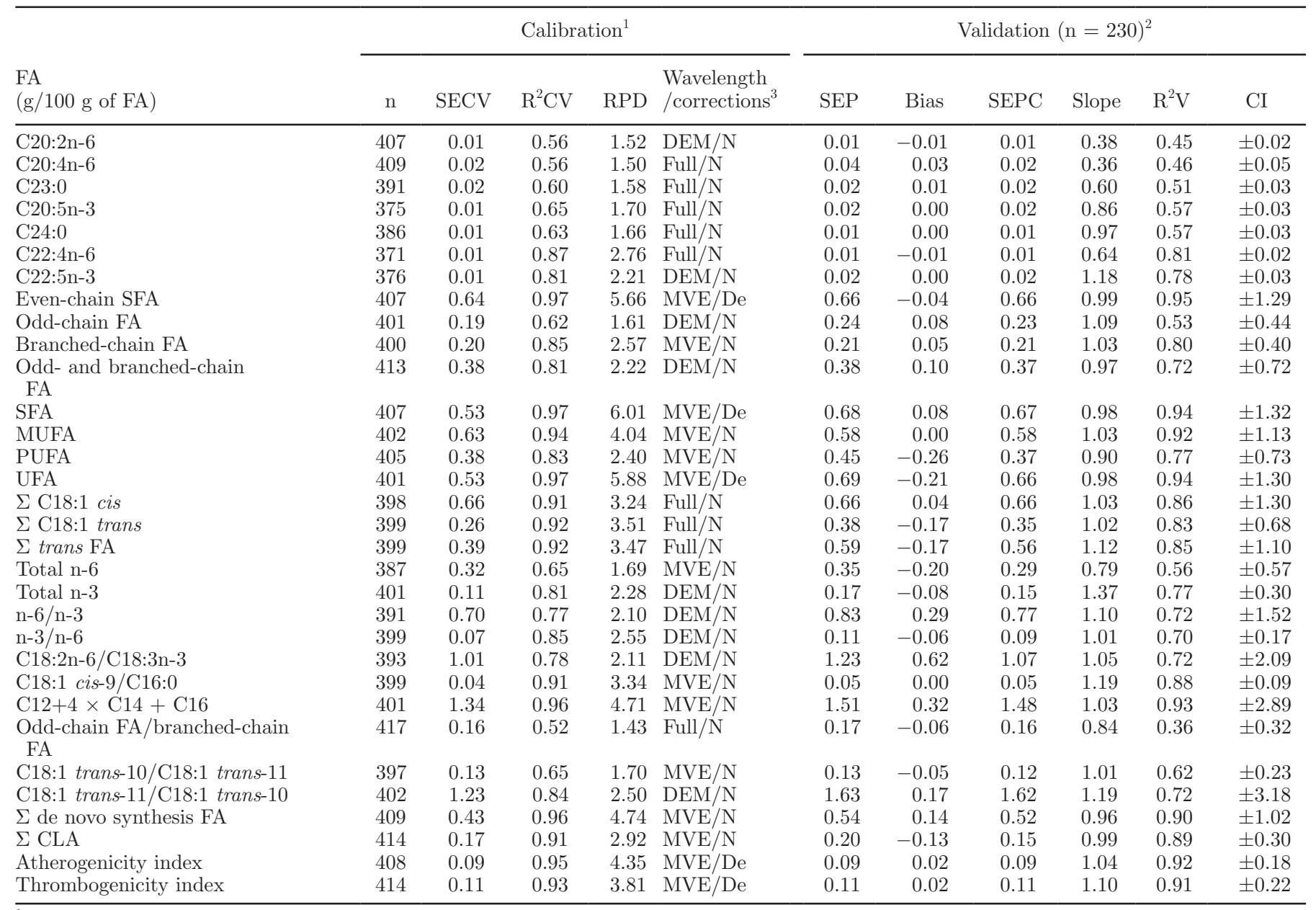

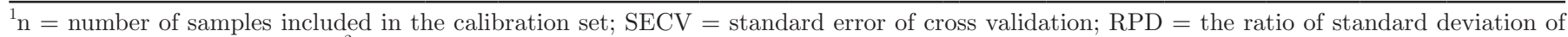
reference data to the $\mathrm{SECV} ; \mathrm{R}^{2} \mathrm{CV}=$ coefficient of determination in cross-validation.

${ }^{2} \mathrm{SEP}=$ standard error of prediction in external validation; SEPC $=\mathrm{SEP}$ corrected for the bias; $\mathrm{R}^{2} \mathrm{~V}=$ coefficient of determination in external validation; $\mathrm{CI}=$ confidence interval at $P=0.95(=\mathrm{SEPC} \times 1.96)$.

${ }^{3} \mathrm{MVE}$ = wavelength intervals used by Maurice-Van Eijndhoven et al. (2013); DEM = wavelength intervals used by De Marchi et al. (2011) as the principal mid-infrared regions to estimate milk FA composition; Full = full wavelength spectrum; De = detrend mathematical correction; $\mathrm{N}=$ no mathematical corrections.

overweight of highly correlated FA. Relations between FA within a subpillar were considered relevant when r $>0.90$ (and $P<0.05$ ). In these cases, the theoretical weight was equally split between the correlated FA in each subpillar. Finally, the resulting weights within each subpillar were normalized to achieve an equivalent weight for the 2 pillars, considering them of equivalent importance for the dairy sector. To establish the point ascribed to each class for each FA in a subpillar, the resulting weighs given to each FA in each subpillar (Table 3 ) were divided according to the $\mathrm{n}-1$ classes ( 1 class was attributed to the minimum of zero). The MFAI result for a given milk samples was the sum of the points (on a 0 to 10 scale) achieved for each subpillar.

\section{MFAI Simulations}

The MFAI was tested to define a premium payment system for a commercial dairy plant in Piedmont (Italy). Calculations of MFAI were performed on the milk from the dairy farms that deliver milk to the selected dairy plant and had not been included in the data set from which the equations were developed. Two farming systems were identified: intensive dairy farms, which are representative of the Po plain, and extensive farms, located in the mountainous and hilly areas in northwest Italy. The feeding strategy of the intensive dairy farms, which were applied all year round, differed according to the diets of the dairy cows. These diets were mainly 

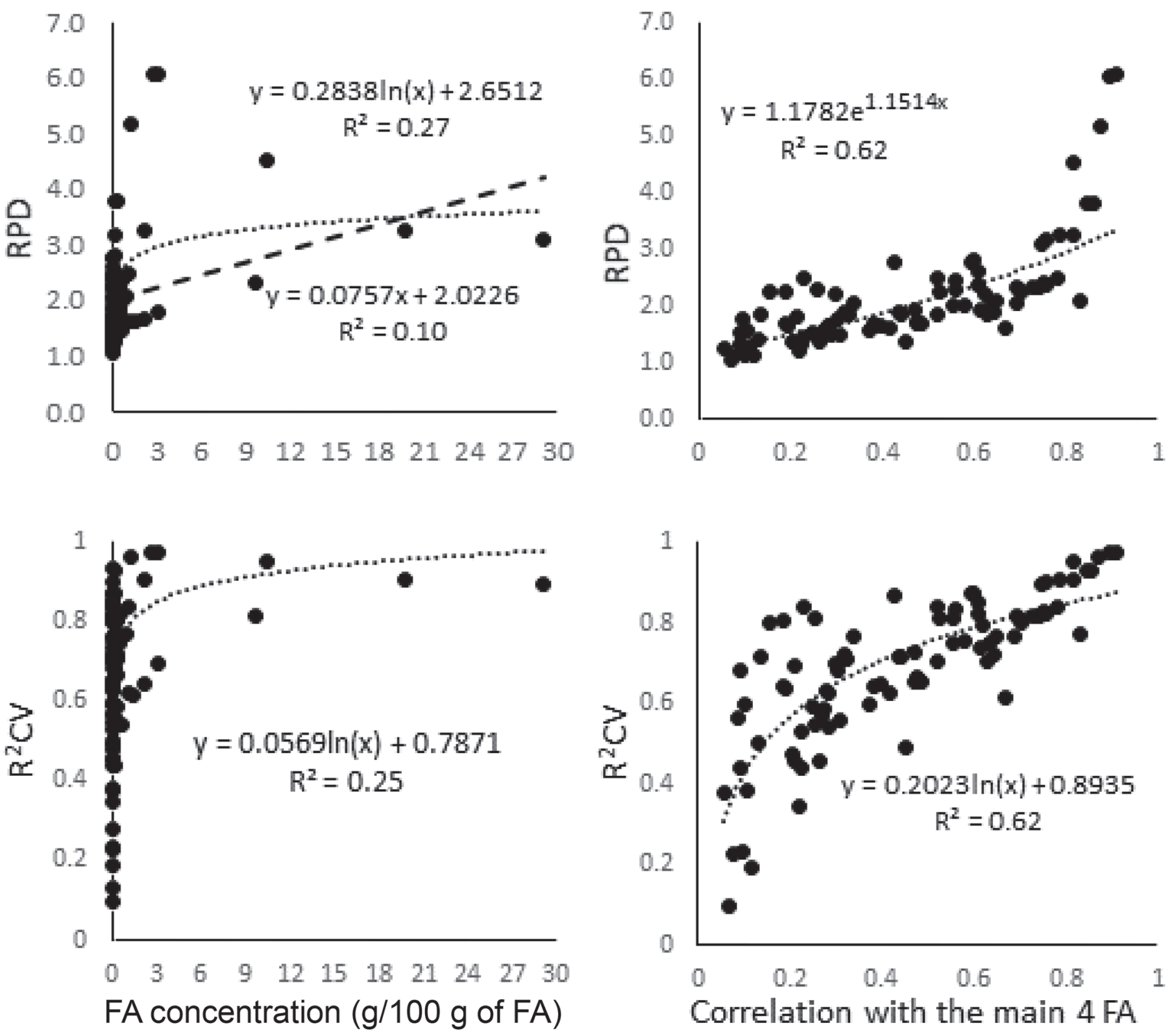

Figure 1. Variation of ratio of standard deviation of reference data to the standard error of cross-validation (RPD) and coefficient of determination for cross-validation $\left(\mathrm{R}^{2} \mathrm{CV}\right.$ ) as a function of individual fatty acid (FA) concentration in grams per $100 \mathrm{~g}$ of $\mathrm{FA}$ (on the left side) and of the best correlation of individual FA concentration ( $\mathrm{g} / 100 \mathrm{~g}$ of FA) with the concentration $(\mathrm{g} / 100 \mathrm{~g}$ of FA) of 1 of the main 4 FA in milk (C14:0, C16:0, C18:0, and C18:1 cis-9; on the right side).

based on corn silage, grass or legume silages (produced on farm), and a large proportion of concentrates (about 30 to $50 \%$ on a DM basis), almost all of which was purchased off farm. The extensive farms adopted 2 different feeding strategies, 1 in winter and 1 during the grazing season. Their forage system was based on grazing in the vegetative growing season (with a fresh herbage proportion in the cow diet ranging from 45 to $100 \%$ on a DM basis), and in some cases was supplemented by hay (mainly produced on farm) and small proportions of purchased concentrates (about 10\% on a DM basis), or on hay (mainly produced on farm) and a low proportion of purchased concentrates (about 15\% on a DM basis) in the winter period.

\section{Reference Data}

The descriptive statistics of the GC data pertaining to the FA and their sums and ratios in the calibration 
and validation sample sets are reported in Table 4 . The mean values and the standard deviation of all the FA and sums are similar for the 2 sets.

\section{Prediction Equations}

The calibration and validation statistics obtained for the individual FA, the FA sums and ratios, as well as the statistical treatment and wavelength intervals that showed the best results in the calibration are shown in Table 5. Among the SFA, C6:0, C8:0, C10:0, C12:0, C14:0, and C16:0 were successfully predicted by MIRS, with $\mathrm{R}^{2} \mathrm{CV} \geq 0.91$ and $\mathrm{RPD}>2.5$. The predictions for C5:0, C7:0, C9:0, C11:0, C18:0, C19:0, and C20:0 were found to be promising $\left(\mathrm{R}^{2} \mathrm{CV} \geq 0.81\right)$. The best predictions among the individual BCFA were observed for iso $\mathrm{C} 14: 0$, iso $\mathrm{C} 15: 0$, anteiso $\mathrm{C} 15: 0$, and iso $\mathrm{C} 17: 0+$ C16:1 trans-9, and they were found to be promising. The predictions of the individual MUFA were reliable $\left(\mathrm{R}^{2} \mathrm{CV}>0.90\right)$ for $\mathrm{C} 10: 1$ cis-9, $\mathrm{C} 12: 1$ cis-9, and $\mathrm{C} 18: 1$ cis-9, and promising for $\mathrm{C} 16: 1$ trans-6/7/8, C16:1 cis11, C18:1 trans-11, C18:1 trans- $12+$ cis-6, C18:1 cis- 12 , and C18:1 cis-14. Among the individual PUFA, C18:1 trans-11,cis-15, CLA cis-9,trans-11 + trans-7,cis-9 + trans-8, cis-10, C22:4 n-6, and C22:5 n-3 showed promising equations. Reliable or promising predictions were found for several FA with low concentrations in the milk (i.e., C18:2 trans-11,cis-15, C20:0, C22:4 n-6), whereas some of the FA with higher concentrations in the milk were poorly predicted (i.e., C16:1 cis-9 and C15:0; $\left.\mathrm{R}^{2} \mathrm{CV}<0.66\right)$.

The C14:1 trans-9, C16:1 trans-5, C16:1 cis-10, C18:1 cis-13, C18:1 cis-15; C18:1 cis-16, C19:1 cis-10, C18:3 n-6, C20:1 cis-11, CLA trans-11,trans-13, C22:0, C20:3 n-6, C20:3 n-3 + C22:1 cis-13, C22:3 n-3 + C24:1 cis-9, $\mathrm{C} 22: 6$ n-3, and C14:1 cis-9-to-C14:0 FA showed very poor predictions $\left(R^{2} \mathrm{~V}<0.40\right)$, and for this reason the calibration and validation statistics have not been shown.

The relationship between the $\mathrm{RPD}$ or $\mathrm{R}^{2} \mathrm{CV}$ of all the individual FA and their concentrations, expressed as grams per $100 \mathrm{~g}$ of $\mathrm{FA}$, was poor $\left(\mathrm{R}^{2}<0.30\right.$; Figure 1). On the other hand, significant relationships were observed between the prediction performance of some individual FA and their correlations with the concentration of at least one of the 4 main milk FA (C14:0, C16:0, C18:0, and C18:1 cis-9; Figure 1), with $\mathrm{R}^{2}=$ 0.62 for both RPD (exponential relation) and $\mathrm{R}^{2} \mathrm{CV}$ (logarithmic relation). The correlation between most of the individual FA and the milk fat content was either not significant or poor (data not shown), except for the 4 main FA, which showed correlation coefficients of between 0.25 and 0.36 . 
Table 7. Simulation of the calculation of milk fatty acid index (MFAI) for intensive farming systems ${ }^{1}$ in a group of farms delivering milk to the selected dairy plant and corresponding milk fatty acid (FA) concentrations $\left(\mathrm{g} / 100 \mathrm{~g}\right.$ of FA) ${ }^{2}$

\begin{tabular}{|c|c|c|c|c|c|c|c|c|c|c|c|c|c|c|c|}
\hline Item & \multicolumn{5}{|c|}{ Farm 1} & \multicolumn{5}{|c|}{ Farm 2} & \multicolumn{5}{|c|}{ Farm 3} \\
\hline C18:3 n-3 & 0.23 & 0 & & & 0 & 0.31 & 0 & & & 0 & 0.85 & 0.06 & & & 0.21 \\
\hline CLA cis- 9, trans- 11 & 0.56 & 0 & & & 0 & 0.64 & 0 & & & 0 & 0.81 & 0.33 & & & 0.28 \\
\hline Even-chain SFA & 63.9 & 0 & 0 & & & 60.79 & 0.17 & 0.09 & & & 58.17 & 0.25 & 0.14 & & \\
\hline PUFA & 3.79 & 0 & 0 & & & 4.74 & 0 & 0 & & & 6.58 & 0.33 & 0.28 & & \\
\hline Total n-3 & 0.37 & 0 & & & & 0.47 & 0 & & & & 1.03 & 0.08 & & & \\
\hline n-3/n-6 & 0.17 & 0 & & & & 0.17 & 0 & & & & 0.27 & 0 & & & \\
\hline C18:1 cis-9/C16:0 & 0.58 & & 0 & & & 0.68 & & 0.09 & & & 0.28 & & 0.18 & & \\
\hline $\begin{array}{l}\text { C18:1 trans-10/C18:1 } \\
\text { trans-11 }\end{array}$ & 0.66 & & & 0.56 & & 0.56 & & & 0.56 & & 0.8 & & & 0.83 & \\
\hline Total & & 0.08 & 0.05 & 0.56 & 0 & & 0.34 & 0.27 & 0.56 & 0 & & 1.22 & 0.69 & 0.83 & 0.49 \\
\hline
\end{tabular}

${ }^{1}$ Feeding system based on corn silage, grass or legume silages, and a medium or high proportion of concentrate, rearing high-yielding cow breeds.

${ }^{2} \mathrm{AW}=$ animal welfare; DPSP = dairy products sensory properties; ES = environmental sustainability; HH = human health pillar.

\section{Implication for the Practical Use of FA Prediction Equations}

In the class-based approach that is proposed in the present study, each class has a central FA concentration value and an upper and lower limit, determined by the CI to overcome the performance limit of the proposed equations. The larger the range of variation of a FA, the larger the number of classes. The nominal values and the limits of the classes for the FA selected for the calculation of the MFAI are reported in Table 6. The number of classes, other than class 0 , ranged from 1 to 6 for the sums or ratios of the FA and from 1 to 5 for the individual FA and was inversely proportional to the SEP.

\section{Application Examples of the Milk FA Index}

The simulations of the MFAI calculations for the 10 selected FA are reported in Table 7 for the selected feeding strategies that were analyzed. In the intensive dairy farming system, MFAI ranged from 0.7 to 3.2 . In the extensive farming system, MFAI ranged from 3.5 to 4.5 during winter and from 3.5 to 8.2 during the grazing season (Table 8).

\section{DISCUSSION}

\section{Prediction Equations}

To the best of our knowledge, no calibration equations obtained from MIRS, such as those reported in the present paper, have been published before pertaining to a detailed FA profile. Our calibrations have shown comparable or even better performances than those found in literature for the main FA sums and ratios and for the individual FA predicted as grams per $100 \mathrm{~g}$ of FA (Soyeurt et al., 2011; Ferrand-Calmels et al., 2014; Lopez-Villalobos et al., 2014); however, Stefanov et al. (2011), working on the determination of a few trans isomers of $\mathrm{C} 18: 1$ and $\mathrm{C} 18: 2$, found better performances using Fourier transform Raman spectroscopy. Stefanov et al. (2011) only developed equations for a few individual milk samples collected from cows receiving lipid supplements in doses that are not commonly used on farms and are known to have a profound effect on the milk FA profile (Chilliard et al., 2007). Therefore, the prediction performances of those equations decreased when the samples derived from the diets with lipid supplement were excluded (Stefanov et al., 2011), and similar $\mathrm{R}^{2} \mathrm{CV}$ and $\mathrm{RPD}$ values to those obtained in the present research were reached.

The advantages of setting the calibration of FA expressed as grams per $100 \mathrm{~g}$ of FA rather than as proportions of milk have already been discussed by Coppa et al. (2014). The calculation of milk FA as grams per kilogram of milk implies the introduction of a correction for the milk fat content, which is already one of the parameters considered to determine milk prices in breeding programs, and it is usually standardized during milk processing (Coppa et al., 2014). Furthermore, the published MIRS calibration of FA, expressed as grams per kilogram of milk, were developed on milk from individual cows (Soyeurt et al., 2006; MauriceVan Eijndhoven et al., 2013; Ferrand-Calmels et al., 2014). As the fat content of individual milk can vary 
MID-INFRARED FATTY ACID ANALYSES TO VALORIZE MILK

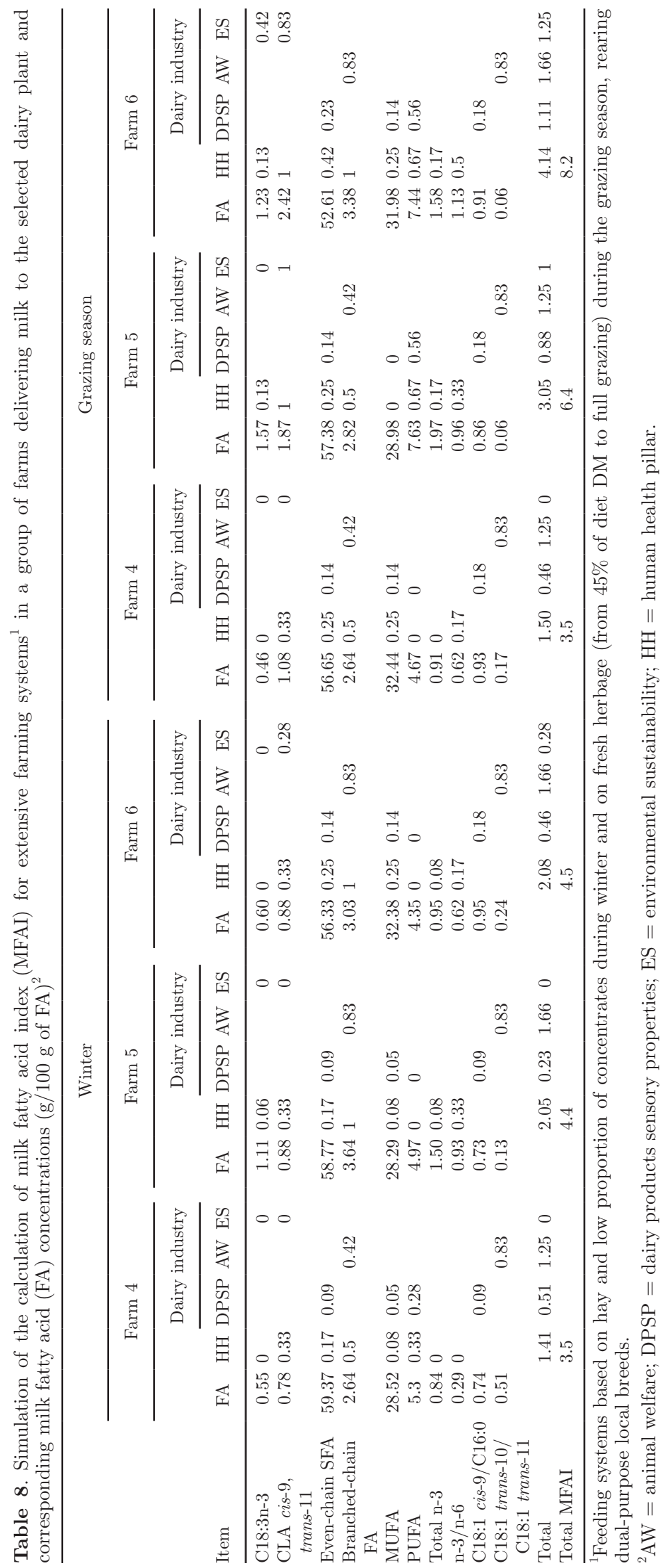


considerably among individuals and can reach extreme values, expressing FA as grams per kilogram of milk can result in an apparent (but not real) large variation in the milk FA content (Coppa et al., 2014). The collection of a data set of bulk milk from a wide range of production conditions allowed variations in FA profiles to be obtained that are comparable to or even larger than those obtained from individual milk samples and used to develop MIRS equations for FA (Soyeurt et al., 2011; Maurice-Van Eijndhoven et al., 2013; FerrandCalmels et al., 2014). Thus, in the present research, calibrating equations on the bulk milk FA composition expressed as grams per $100 \mathrm{~g}$ of FA can be considered a new approach that reinforces the reliability of our results and their transferability to routine applications for milk payment, as dairy plants set their milk prices on the basis of the bulk milk composition. Soyeurt et al. (2006), Rutten et al. (2009), and De Marchi et al. (2011) showed that the RPD and $\mathrm{R}^{2} \mathrm{CV}$, as the expression of the quality of prediction performance of the main individual FA and their sums, increased with the FA (or the sum of the FA) concentrations in milk. Thus, Soyeurt et al. (2006) suggested that FA exhibit an absorbance at a specific wavelength and that the reliability of mid-infrared prediction is related to that specific absorbance, implying that minor FA in milk have too low a concentration to affect the absorbance and consequently to obtain reliable predictions by means of MIRS.

However, considering a larger number of FA (and excluding their sums), the close relationship that was found between the concentration of at least 1 of the 4 main milk FA and the RPD or $\mathrm{R}^{2} \mathrm{CV}$ of individual FA, seems to suggest that a good prediction could also be possible for minor FA, because of their indirect correlation to C14:0, C16:0, C18:0, and C18:1 cis-9. According to Soyeurt et al. (2006), these 4 main FA are the ones that are the most closely correlated with the milk fat content (together reaching more than $70 \%$ of the total milk FA). This would seem to suggest that their good prediction could be the result of their correlation to the total fat content, and that the prediction of the other FA may be the result of the correlation to 1 of the 4 main FA rather than of a real absorbance specific of FA, as their correlations to the milk fat content were found to be poor or not significant.

\section{Implication for the Practical Use of FA Prediction Equations}

In recent years, several papers have proposed predictive equations of the composition of milk FA by MIRS (Maurice-Van Eijndhoven et al., 2013; Coppa et al.,
2014; Ferrand-Calmels et al., 2014). In some countries, these equations are still used routinely to determine the milk concentration of some milk FA, the sum of FA, and the FA ratios, on which supplementary premiums for farmers are calculated (Borreani et al., 2013). However, it has been demonstrated in the literature (i.e., Maurice-Van Eijndhoven et al., 2013; Coppa et al., 2014; Ferrand-Calmels et al., 2014) that only some FA can be reliably predicted by MIRS. Even though some improvements to FA could still be possible, equations that show a high SEP ought to be used with caution.

The present study aimed at overcoming these performance limits by proposing a method that would lead to the confident use of almost all the equations to predict the milk FA profile. The determination of the median (assumed as class 0 in the proposed method), as well as the minimum and maximum values, is the key point of the method, and implies the construction of a database of bulk milk samples on which the equations have to be applied to determine the FA concentrations. The first requirement is that the database is representative of the heterogeneity of the farming systems and feeding strategies operating in the area where the methods have to be applied, as far as both the frequency of a given farming system and the amount of milk that it produces are concerned. The correspondence of the class distribution to the sample population distribution depends on the structure of the heterogeneity and the frequency of the various farming and feeding systems in a specific area. However, as the classes are set on the basis of the precision of the prediction equations, the distribution of the population would not affect the reliability of the class approach estimation, requiring caution by end users. One milk sample per month for 2 yr from among those used for the routine milk analyses by MIRS for the standard-quality premium payment could be a good base for the construction of the database; this would allow the seasonal and between-year variations in cow feeding that are adopted mainly by farming systems based on grazing to be covered (Butler et al., 2011).

This method has proven to be adaptable to several production areas, as the median, minimum, and maximum values can vary according to the production conditions applied in each specific context. According to the breeding purposes, as well as the local marketing and production strategies (i.e., C18:1 cis-9/C16:0 would be of no interest for dairy plants that sell liquid milk), the actors involved in the milk production chain could select which pool of FA should be used for the calculation of the MFAI. Furthermore, each actor could establish the minimum and maximum thresholds of the sum of MFAI, from which the premium pay- 
ment would be calculated. As a result, MFAI could be a good tool to satisfy the requirements of the actors involved in the milk production chain. To calculate the milk supplementary premium on the basis of a better FA profile, the MFAI can be multiplied by a monetary value (defined in agreement with the actors of the dairy production chain).

The importance of having a tool that is able to define premium payments for those farmers that increase the UFA concentration of milk fat at a farm level has recently been pointed out by Silva-Villacorta et al. (2016), who proposed a model to define the impact of increasing the fat UFA concentration on the physical and financial performances of dairy farms. The index proposed in the present work has been used to apply a premium payment system for a commercial dairy plant in Piedmont (Italy), which was introduced with the aim of diversifying the dairy production to obtain new products from milk with an high MFAI. The calculation of MFAI on the dairy farms that deliver milk to the dairy plant showed a large variation for both intensive and extensive farms. One intensive farm showed a MFAI close to that of extensive dairy farming systems during the winter period. This result opens an interesting perspective concerning the possibility of improving the nutritional quality of Italian milk and the environmental sustainability of dairy farming systems, as about $80 \%$ of Italian milk is produced on intensive farms (Borreani et al., 2013). The introduction of a premium based on MFAI would help to increase the competitiveness and the sustainability of the dairy farms that adopt high-quality homegrown grass and legume forages as alternatives to corn silage and concentrates (Borreani et al., 2013).

A wide range of variation of the MFAI of milk from extensive farms that apply a winter feeding system, based on hay, was found. This could depend on the nutritive quality of the hay, which can vary to a great extent between years (Butler et al., 2011) according to the stage of growth at cutting, the weather conditions during field wilting, and the conservation practices adopted (Baumont et al., 2007; Borreani et al., 2007).

Similar considerations can be made for pasture-based farming systems, for which the milk MFAI was found to had an extensive range of variation that depended on the fresh herbage proportion in the cow diet and the herbage quality (Coppa et al., 2015b). This suggests that the fresh herbage proportion in a cow diet and herbage quality need to be managed to improve the nutritional quality of the milk FA profile (Coppa et al., 2015a,b). Herbage quality is a strategic factor that has to be managed on a farm to achieve high MFAI scores without lowering the performance of the herd.
The fresh herbage characteristics, such as an early phenological stage, a high leaf-to-stem ratio, or a high nutritive value, can positively affect the concentration of health-promoting FA in milk (Coppa et al., 2015b) and can thus increase MFAI. Similar considerations can be made for the herbage botanical composition, which is known to affect milk FA concentrations (Adler et al., 2013; Coppa et al., 2015b). These results underline the key role of the diet composition and forage quality and composition on both intensive and extensive dairy farms, in determining the milk FA profile (Borreani et al., 2013; Coppa et al., 2015b) and, consequently, the MFAI.

\section{CONCLUSIONS}

This work presents prediction equations, obtained from MIRS, that can be used to establish a detailed FA composition of milk, and shows that the prediction performances are related to the correlation of the minor FA to the 4 main FA in milk. A method for adding value to milk, based on these equations, has been proposed. The MFAI can include FA that are important for human health or nutrition or for the sensory properties of dairy products, as well as FA indicators of the animal welfare or environmental sustainability of the farming systems, depending on the ultimate product description or marketing type. The proposed method is flexible and adaptable to several contexts (i.e., farming system and practices, dairy production, and marketing strategies). The studied examples have highlighted the sensitivity and applicability of MFAI to both intensive and extensive farming systems in which different feeding strategies are adopted.

\section{ACKNOWLEDGMENTS}

This work was supported by Fondazione Cassa di Risparmio di Cuneo (CRC), Project "MIGLIORLAT - Miglioramento della qualità e dello sviluppo competitivo della filiera latte piemontese," Bando Ricerca Scientifica 2011 and by POR-FESR Asse I Attività I.1.3 Innovazione e P.M.I., Project "SISTFORM - Sistemi foraggeri prativi a basso impatto per la valorizzazione del latte caseificato in formaggi tipici della montagna piemontese: analisi per lo sviluppo di una linea di produzione ad elevato valore nutrizionale," Studi di fattibilità 2014 (Regione Piemonte, Turin, Italy). Authors also thank Fabrizio Turina (Caseificio Montoso of Bagnolo Piemonte, CN, Italy), Guido Finessi, Elio Fiori, and Aldo Trabona (ARAP - Torino, Italy) for the MIR analysis, and FOSS (Hillerød, Denmark) for the technical support in the use of MIR. 


\section{REFERENCES}

Adler, S. A., A. V. Dahl, S. K. Jensen, E. Thuen, A.-M. Gustavsson, and H. Steinshamn. 2013. Fatty acid composition, fat-soluble vitamin concentrations and oxidative stability in bovine milk produced on two pastures with different botanical composition. Livest. Sci. 154:93-102. https://doi.org/10.1016/j.livsci.2013.03.013.

Arnould, V. M.-R., R. Reding, J. Bormann, N. Gengler, and H. Soyeurt. 2013. Review: Milk composition as management tool of sustainability. Biotechnol. Agron. Soc. Environ. 17:613-621.

Bauman, D. E., and J. M. Griinari. 2003. Nutritional regulation of milk fat synthesis. Annu. Rev. Nutr. 23:203-227.

Baumont, R., J. P. Dulphy, D. Sauvant, G. Tran, F. Meschy, J. Aufrère, J. L. Peyraud, and P. Champciaux. 2007. Les tables de la valeur des aliments. Pages 181-275 in Alimentation des Bovins, Ovins et Caprins. Besoins des Animaux-Valeur des Aliments. INRA ed., Editions Quae, Versailles, France.

Borreani, G., M. Coppa, A. Revello-Chion, L. Comino, D. Giaccone, A. Ferlay, and E. Tabacco. 2013. Effect of different feeding strategies in intensive dairy farming systems on milk fatty acid profile, and implications on feeding costs in Italy. J. Dairy Sci. 96:68406855. https://doi.org/10.3168/jds.2013-6710.

Borreani, G., D. Giaccone, A. Mimosi, and E. Tabacco. 2007. Comparison of hay and haylage from permanent Alpine meadows in winter dairy cow diets. J. Dairy Sci. 90:5643-5650. https://doi .org/10.3168/jds.2007-0134.

Butler, G., S. Stergiadis, C. Seal, M. Eyre, and C. Leifert. 2011. Fat composition of organic and conventional retail milk in northeast England. J. Dairy Sci. 94:24-36. https://doi.org/10.3168/jds.2010 $-3331$.

Caramia, G. M., and E. Ruffini. 2005. L'acido docosaesaenoico (DHA): Aspetti fisiopatologici e prospettive terapeutiche. Pages 2-13 in Proc. XXII Int. Congr., Bambino: Progetto Salute. G. M. Caramia, ed. Accessed Aug. 22, 2016. http://www.bambinoprogettosalute .it/sites/default/files/relazione_caramia.pdf.

Chilliard, Y., A. Ferlay, and M. Doreau. 2001. Effect of different types of forages, animal fat or marine oils in cow's diet on milk fat secretion and composition, especially conjugated linoleic acid (CLA) and polyunsaturated fatty acids. Livest. Prod. Sci. 70:31-48. https://doi.org/10.1016/S0301-6226(01)00196-8.

Chilliard, Y., F. Glasser, A. Ferlay, L. Bernard, J. Rouel, and M Doreau. 2007. Diet, rumen biohydrogenation and nutritional quality of cow and goat milk fat. Eur. J. Lipid Sci. Technol. 109:828 855. https://doi.org/10.1002/ejlt.200700080.

Coppa, M., C. Chassaing, A. Ferlay, C. Agabriel, C. Laurent, G. Borreani, R. Barcarolo, T. Baars, D. Kusche, O. M. Harstad, J. Verbič J. Golecký, C. Delavaud, Y. Chilliard, and B. Martin. 2015a. Potential of milk fatty acid composition to predict diet composition and authenticate feeding systems and altitude origin of European bulk milk. J. Dairy Sci. 98:1539-1551. https://doi.org/10.3168/ jds.2014-8794.

Coppa, M., A. Ferlay, G. Borreani, A. Revello-Chion, E. Tabacco, G. Tornambé, P. Pradel, and B. Martin. 2015b. Effect of phenological stage and proportion of fresh herbage in cow diets on milk fatty acid composition. Anim. Feed Sci. Technol. 208:66-78. https://doi .org/10.1016/j.anifeedsci.2015.07.006.

Coppa, M., A. Revello-Chion, D. Giaccone, A. Ferlay, E. Tabacco, and G. Borreani. 2014. Comparison of near and medium infrared spectroscopy to predict fatty acid composition on fresh and thawed milk. Food Chem. 150:49-57. https://doi.org/10.1016/j.foodchem 2013.10.087.

Dawczynski, C., L. Martin, A. Wagner, and G. Jahreis. 2010. n-3 LCPUFA-enriched dairy products are able to reduce cardiovascular risk factors: A double-blind, cross-over study. Clin. Nutr. 29:592599. https://doi.org/10.1016/j.clnu.2010.02.008.

De Marchi, M., M. Penasa, A. Cecchinato, M. Mele, P. Secchiari, and G. Bittante. 2011. Effectiveness of mid-infrared spectroscopy to predict fatty acid composition of Brown Swiss bovine milk. Animal 5:1653-1658. https://doi.org/10.1017/S1751731111000747.
De Marchi, M., V. Toffanin, M. Cassandro, and M. Penasa. 2014. Midinfrared spectroscopy as phenotyping tool for milk traits. J. Dairy Sci. 97:1171-1186. https://doi.org/10.3168/jds.2013-6799.

Diekman, C., and K. Malcolm. 2009. Consumer perception and insights on fats and fatty acids: Knowledge on the quality of diet fat. Ann. Nutr. Metab. 54(Suppl. 1):25-32. https://doi.org/10.1159/ 000220824.

Dilzer, A., and Y. Park. 2012. Implication of conjugated linoleic acid (CLA) in human health. Crit. Rev. Food Sci. Nutr. 52:488-513. https://doi.org/10.1080/10408398.2010.501409.

Enjalbert, F. Y. Videau, M. C. Nicot, and A. Troegeler-Meynadier. 2008. Effects of induced subacute ruminal acidosis on milk fat content and milk fatty acid profile. J. Anim. Physiol. Anim. Nutr. (Berl.) 92:284-291. https://doi.org/10.1111/j.1439-0396.2007 .00765.x.

Ferrand-Calmels, M., I. Palhière, M. Brochard, O. Leray, J. M. Astruc, M. R. Aurel, S. Barbey, F. Bouvier, P. Brunschwig, H. Caillat, M. Douguet, F. Faucon-Lahalle, M. Gelé, G. Thomas, J. M. Trommenschlager, and H. Larroque. 2014. Prediction of fatty acid profiles in cow, ewe, and goat milk by mid-infrared spectrometry. J. Dairy Sci. 97:17-35. https://doi.org/10.3168/jds.2013-6648.

Food and Agriculture Organization of the United Nations (FAO) 2016. Statistical dataset. Accessed Aug. 22, 2016. http://faostat .fao.org/site/610/DesktopDefault.aspx?PageID =610\#ancor.

Giaccone, D., A. Revello-Chion, L. Galassi, P. Bianchi, G. Battelli, M Coppa, E. Tabacco, and G. Borreani. 2016. Effect of milk thermisation and farming system on cheese sensory profile and fatty acid composition. Int. Dairy J. 59:10-19. https://doi.org/10.1016/ j.idairyj.2016.02.047.

Givens, D. I. 2010. Milk and meat in our diet: Good or bad for health? Animal 4:1941-1952. https://doi.org/10.1017/S1751731110001503.

Guyonnet, J. P. 1989. Les Beurres Français-Tartinabilité et Composition. Doc. Association pour le développement de la Recherche dans l'Industrie Laitière, Paris, France.

Hurtaud, C., M. Dutreuil, M. Coppa, C. Agabriel, and B. Martin. 2014. Characterization of milk from feeding systems based on herbage or corn silage with or without flaxseed and authentication through fatty acid profile. Dairy Sci. Technol. 94:103-123. https:// doi.org/10.1007/s13594-013-0147-0.

IDF. 2000. Whole milk-Determination of milkfat, protein and lactose content-Guidance on the operation of mid-infrared instruments. IDF 141C:2000. International Dairy Federation, Brussels, Belgium.

Kirkwood, B. R., and J. A. C. Sterne. 2003. Essential Medical Statistics. 2nd ed. Blackwell Science Ltd., Oxford, UK.

Lopez-Villalobos, N., R. J. Spelman, J. Melis, S. R. Davis, S. D. Berry K. Lehnert, S. E. Holroyd, A. K. H. MacGibbon, and R. G. Snell. 2014. Estimation of genetic and crossbreeding parameters of fatty acid concentrations in milk fat predicted by mid-infrared spectroscopy in New Zealand dairy cattle. J. Dairy Res. 81:340-349. https://doi.org/10.1017/S0022029914000272.

Mantha, S., R. Thisted, J. Foss, J. E. Ellis, and M. F. Roizen. 1993 A proposal to use confidence intervals for visual analog scale data for pain measurement to determine clinical significance. Anesth. Analg. 77:1041-1047.

Martin, B., I. Verdier-Metz, S. Buchin, C. Hurtaud, and J. B. Coulon. 2005. How does the nature of forages and pastures diversity influence the sensory quality of dairy livestock products? Anim. Sci. 81:205-212. https://doi.org/10.1079/ASC50800205.

Maurice-Van Eijndhoven, M. H. T., H. Soyeurt, F. Dehareng, and M. P. L. Claus. 2013. Validation of fatty acid predictions in milk using mid-infrared spectroscopy across cattle breeds. Animal 7:348-354. https://doi.org/10.1017/S1751731112001218.

Nardo, M., M. Saisana, A. Saltelli, S. Tarantola, A. Hoffman, and E. Giovannini. ed. 2008. Handbook on Constructing Composite Indicators: Methodology and User Guide. Organisation for Economic Cooperation and Development and European Commission Joint Research Centre. OECD, Paris, France.

Paracchini, M. L., C. Bulgheroni, G. Borreani, E. Tabacco, A. Banterle, D. Bertoni, G. Rossi, G. Parolo, R. Origgi, and C. De Paola 2015. A diagnostic system to assess sustainability at a farm level: 
The SOSTARE model. Agric. Syst. 133:35-53. https://doi.org/10 .1016/j.agsy.2014.10.004.

Parodi, P. W. 2004. Milk fat in human nutrition. Aust. J. Dairy Technol. 59:3-59.

Peeters, A. 2012. Past and future of European grasslands. The challenge of the CAP towards 2020. Pages 17-32 in Grassland: An European Resource? Grassland Science in Europe Vol. 17: Proceedings of the 24th General Meeting of the European Grassland Federation. Golínski, P., Warda, M., Stypínski, P. ed. Polish Grassland Society, Warsaw, Poland.

Revello-Chion, A., E. Tabacco, D. Giaccone, P. G. Peiretti, G. Battelli, and G. Borreani. 2010. Variation of fatty acid and terpene profile in mountain milk and "Toma piemontese" cheese as affected by diet composition in different seasons. Food Chem. 121:393-399. https://doi.org/10.1016/j.foodchem.2009.12.048.

Rutten, M. J. M., H. Bovenhuis, K. A. Hettinga, H. J. F. van Valenberg, and J. A. M. van Arendonk. 2009. Predicting bovine milk fat composition using infrared spectroscopy based on milk samples collected in winter and summer. J. Dairy Sci. 92:6202-6209. https://doi.org/10.3168/jds.2009-2456.

Shenk, J. S. 1989. Monitoring analysis results. Pages 27-28 in Near Infrared Reflectance Spectroscopy (NIRS): Analysis of Forage Quality. G. C. Marten, J. S. Shenk, and F. E. Barton ed. USDA, Springfield, VA.

Shenk, J. S., and M. O. Westerhaus. 1995. Analysis of agriculture and food products by near infrared reflectance spectroscopy. Monograph, NIR Systems Inc., Pennsylvania State University, and Owners of Infrasoft International. Silver Spring, MD.

Shingfield, K. J., M. Bonnet, and N. D. Scollan. 2013. Recent developments in altering the fatty acid composition of ruminantderived foods. Animal 7:132-162. https://doi.org/10.1017/ S1751731112001681.

Silva-Villacorta, D. 2014. Determining premium payments for concentration of unsaturated fatty acids in milkfat in New Zealand based on changes in farm and processor profit. PhD Thesis. Animal Science Department, Massey University, Palmerston North, New Zealand.

Silva-Villacorta, D., N. Lopez-Villalobos, H. T. Blair, R. E. Hickson, and A. K. MacGibbon. 2016. A stochastic farm model to simulate dairy farms and the segregation of cows to produce milk with different concentrations of unsaturated fatty acids. Comput. Electron. Agric. 125:29-38. https://doi.org/10.1016/j.compag.2016.04 .021 .

Soyeurt, H., P. Dardenne, F. Dehareng, G. Lognay, D. Veselko, M. Marlier, C. Bertozzi, P. Mayeres, and N. Gengler. 2006. Estimating fatty acid content in cow milk using mid-infrared spectrometry. J. Dairy Sci. 89:3690-3695. https://doi.org/10.3168/jds.S0022 -0302(06)72409-2.

Soyeurt, H., F. Dehareng, N. Gengler, S. McParland, E. Wall, D. P. Berry, M. Coffey, and P. Dardenne. 2011. Mid-infrared prediction of bovine milk fatty acids across multiple breeds, production systems, and countries. J. Dairy Sci. 94:1657-1667. https://doi.org/ $10.3168 /$ jds.2010-3408.

Stark, A. H., M. A. Crawford, and R. Reifen. 2008. Update on

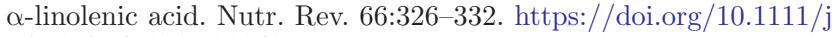
.1753-4887.2008.00040.x.

Stefanov, I., V. Baeten, O. Abbas, E. Colman, B. Vlaeminck, B. De Baets, and V. Fievez. 2011. Determining milk isolated and conjugated trans-unsaturated fatty acids using Fourier transform Raman spectroscopy. J. Agric. Food Chem. 59:12771-12783. https:// doi.org/10.1021/jf203463r.

Ulbricht, T. L. V., and D. A. T. Southgate. 1991. Coronary heart disease: seven dietary factors. Lancet 338:985-992.

Urbach, G. 1990. Effect of feed on flavor in dairy foods. J. Dairy Sci. 73:3639-3650.

Vlaeminck, B., V. Fievez, A. R. J. Cabrita, A. J. M. Fonseca, and R. J. Dewhurst. 2006. Factors affecting odd- and branched-chain fatty acids in milk: A review. Anim. Feed Sci. Technol. 131:389-417. https://doi.org/10.1016/j.anifeedsci.2006.06.017.

Westerhaus, M. O. 1990. Improving repeatability of NIR calibrations across instruments. Pages 671-674 in Proc. 3rd Int. Conf. Near Infrared Spectrosc., Brussels, Belgium. Agricultural Research Centre, Gembloux, Belgium.

Williams, P. C., and D. C. Sobering. 1993. Comparison of commercial near infrared transmittance and reflectance instruments for analysis of whole grains and seeds. J. Near Infrared Spectrosc. 1:25-32. 